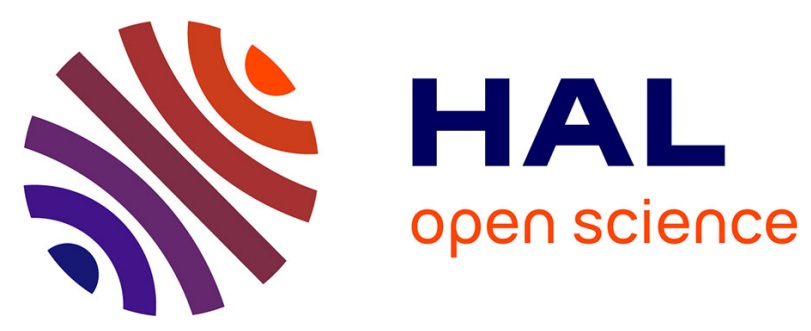

\title{
Pharmacokinetics and pharmacodynamics of tacrolimus in liver transplant recipients: inside the white blood cells
}

Florian Lemaitre, Benoit Blanchet, Marianne Latournerie, Marie Antignac, Pauline Houssel-Debry, Marie-Clémence Verdier, Marine Dermu, Christophe Camus, Jérome Le Priol, Mikael Roussel, et al.

\section{To cite this version:}

Florian Lemaitre, Benoit Blanchet, Marianne Latournerie, Marie Antignac, Pauline Houssel-Debry, et al.. Pharmacokinetics and pharmacodynamics of tacrolimus in liver transplant recipients: inside the white blood cells. Clinical Biochemistry, 2015, 48 (6), pp.406-411. 10.1016/j.clinbiochem.2014.12.018 . hal-01103437

\section{HAL Id: hal-01103437 \\ https://hal-univ-rennes1.archives-ouvertes.fr/hal-01103437}

Submitted on 14 Jan 2015

HAL is a multi-disciplinary open access archive for the deposit and dissemination of scientific research documents, whether they are published or not. The documents may come from teaching and research institutions in France or abroad, or from public or private research centers.
L'archive ouverte pluridisciplinaire HAL, est destinée au dépôt et à la diffusion de documents scientifiques de niveau recherche, publiés ou non, émanant des établissements d'enseignement et de recherche français ou étrangers, des laboratoires publics ou privés. 


\section{Pharmacokinetics and pharmacodynamics of tacrolimus in liver}

transplant recipients: inside the white blood cells.

Florian Lemaitre ${ }^{\mathrm{A}, \mathrm{B}, \mathrm{C}, \mathrm{D}}$, Benoit Blanchet ${ }^{\mathrm{E}}$, Marianne Latournerie ${ }^{\mathrm{C}, \mathrm{F}}$, Marie Antignac ${ }^{\mathrm{D}, \mathrm{G}}$, Pauline Houssel-Debry ${ }^{\mathrm{C}, \mathrm{F}}$, Marie-Clémence $\operatorname{Verdier}^{\mathrm{A}, \mathrm{B}, \mathrm{C}}$, Marine Dermu ${ }^{\mathrm{A}, \mathrm{B}, \mathrm{C}}$, Christophe Camus ${ }^{\mathrm{C}, \mathrm{H}}$, Jérome Le Priol', Mikael Roussel', Yi Zheng ${ }^{\mathrm{E}}$, Pierre Fillatre $^{\mathrm{A}, \mathrm{B}, \mathrm{C}, \mathrm{H}}$, Emmanuel Curis ${ }^{\mathrm{J}, \mathrm{K}}$, Eric Bellissant ${ }^{\mathrm{A}, \mathrm{B}, \mathrm{C}}$, Karim Boudjema ${ }^{\mathrm{C}, \mathrm{L}}$ and Christine Fernandez ${ }^{\mathrm{D}, \mathrm{G}}$.

A. Rennes University Hospital, Department of Clinical and Biological Pharmacology and Pharmacovigilance, Pharmacoepidemiology and Drug Information Centre, Rennes, France.

B. Rennes 1 University, Faculty of Medicine, Laboratory of Experimental and Clinical Pharmacology, Rennes, France.

C. Inserm, CIC-P 1414 Clinical Investigation Centre, Rennes, France.

D. Paris Sud University, Faculty of Pharmacy, EA4123 Barrières physiologiques et réponses thérapeutiques, ChâtenayMalabry, France.

E. Cochin Hospital, Assistance Publique des Hôpitaux de Paris (AP-HP), Pharmacokinetics and pharmacochemistry Department, Paris, France.

F. Rennes University Hospital, Liver Disease Unit, Rennes, France.

G. Saint-Antoine Hospital, Assistance Publique des Hôpitaux de Paris (AP-HP), Pharmacy Department, Paris, France.

H. Rennes University Hospital, Intensive Care Medicine Unit, Rennes, France.

I. Rennes University Hospital, Haematology Department, Rennes, France.

J. Paris Descartes, Sorbonne Paris Cité University, Faculty of Pharmacy, Biomathematics Laboratory, Paris, France.

K. Inserm, Paris Descartes University, Paris Diderot University, UMR-S 1144, Paris, France.

L. Rennes University Hospital, Department of Hepatobiliary and Digestive Surgery, Rennes, France.

Corresponding author: Dr Florian Lemaitre, PharmD. Hôpital Pontchaillou, CHU de Rennes, Service de Pharmacologie, 35033 Rennes cedex, France

Mail: florian.lemaitre@chu-rennes.fr ; tel: 0033.2.99.28.42.80 ; fax: 0033.2.99.28.41.84 


\section{Footnote page:}

\section{Abbreviations:}

ACR: Acute cellular rejection

ALP: Alkaline phosphatise

ALT: Alanine aminotransferase

AST: Aspartate aminotransferase

$\mathrm{AUC}_{0-12}$ : Individual area under the whole blood or intracellular concentration-time curve from 0 to 12 hours

$\mathrm{AUC}_{0-12 \mathrm{CNA}}$ : Individual area under the intracellular calcineurin activity curve from 0 to 12 hours

$\mathrm{C}_{\text {max }}$ : Maximal concentration, peak concentratio

$\mathrm{C}_{12 \mathrm{~h}}:$ Trough concentration

$\mathrm{EC}_{50}$ : Concentration which decreases maximal effect by a half

LC-MS/MS: Liquid chromatography tandem mass spectrometry

PBMC: Peripheral blood mononuclear cells

SEM: Standard error of the mean

SD: Standard deviation

TAC: Tacrolimus

TDM: Therapeutic drug monitoring

WB: Whole blood 


\section{Abstract:}

Objectives: Despite improvements in patient management and extensive use of therapeutic drug monitoring (TDM), the rate of acute cellular rejection (ACR) remains high in patients treated with tacrolimus (TAC). Moreover, some patients experienced ACR while their whole-blood (WB) concentrations were maintained within the therapeutic range meaning that TDM in WB misrepresents the drug effect. Thus, monitoring TAC directly inside of its effect compartment (intracellular concentrations) or monitoring directly the inhibitory effect on the target protein (calcineurin activity) could be more relevant. The aim of the present study was to explore, in 10 de novo liver transplant recipients, the relationship between TAC whole-blood concentrations, TAC intracellular concentrations and TAC-induced intracellular calcineurin inhibition at day 1 and day 7 after treatment initiation.

Design \& Methods: Prospective monocentric observational pharmacokinetic (WB and intracellular concentrations) - pharmacodynamic (calcineurin activity) study.

Results: Full intracellular TAC pharmacokinetic as well as calcineurin activity steadystate profiles are presented in the study. The main result of this study is the lack of relationship between TAC pharmacokinetics (WB and leukocytes) and calcineurin activity in leukocytes at day 1 and day 7 after the graft implantation.

Conclusions: Drug monitoring of TAC intracellular concentrations and determination of the calcineurin activity are among future potential biomarkers of acute rejection in transplant recipients. A better knowledge of the relationship between TAC whole blood and intracellular concentrations and calcineurin activity appears necessary before planning clinical trials to evaluate their potential interest as predictive biomarkers. 
Keywords: Immunosuppressive drugs, therapeutic drug monitoring, peripheral blood mononuclear cells, intracellular, calcineurin 


\section{Introduction:}

Tacrolimus (TAC), a calcineurin inhibitor, is widely used to prevent acute cellular rejection (ACR) after liver transplantation [1]. Despite improvements and research efforts in immunosuppression, the rate of ACR remains frequent, varying from $8 \%$ up to $30 \%$ during the first two years following transplantation [2,3]. Variability in TAC pharmacokinetics might at least partially contribute to liver graft rejection in recipients under TAC. Therapeutic drug monitoring (TDM) based on TAC whole blood concentration assessment is commonly used as a marker to prevent ACR. Besides, a pharmacogenetic approach [4] or a dose individualization based on Bayesian models [5,6] or bottom-up approach [7] may be helpful to further optimize the individualization of TAC dosing in liver transplant recipients. However, it is still uncertain whether these two latter approaches have a significant impact on clinical outcome $[8,9]$. Finally, some patients continue to experience ACR whereas their TAC whole blood concentrations are within the recommended therapeutic range. Although the mechanism underlying such a phenomenon remains unexplained, this suggests that TAC whole blood concentration does not necessarily correlate with the pharmacological effect of TAC on intralymphocyte calcineurin activity. In this context, measurement of intralymphocyte TAC concentrations and/or a pharmacodynamic approach may be helpful to address this issue.

Assaying intralymphocyte TAC concentrations has been proposed to be of possible interest in evaluating the effects of TAC $[10,11]$. Indeed, intra- and inter-variability in TAC binding to erythrocytes and lipoproteins can significantly influence the diffusion of TAC in lymphocytes from liver transplant recipients [12], especially during the first 
two weeks following the graft implantation. Additionally, efflux-drug transporters such as ABCB1 (P-glycoprotein, P-gp) are expressed on the lymphocytes' membrane [13]. TAC is known to be a substrate of ABCB1, which counter-transports TAC out of lymphocytes and back into the whole blood compartment. Therefore, the expression level of $A B C B 1$ can impact TAC disposition in lymphocytes [14], especially in the presence of genetic polymorphisms and/or comedication which can cause an increase or decrease in ABCB1 activity on the membrane. Overall, these different factors contribute to the intra-and inter-individual variability in TAC disposition in lymphocytes. In this context, intralymphocyte TAC concentration could be a better surrogate marker than TAC whole blood concentration to reflect the pharmacodynamic effect of TAC.

Finally, calcineurin activity is considered as one of the most relevant pharmacodynamic biomarkers because it directly reflects the pharmacological effect of TAC on its target [15]. Different investigations carried out in liver transplant recipients treated with TAC have shown that calcineurin activity in peripheral blood mononuclear cells (PBMC) was increased before ACR [16-18]. Despite these promising results, the monitoring of calcineurin activity remains difficult in daily clinical practice for analytical and sample preparation reasons [19].

To our best knowledge, no work has attempted to describe the relationship between TAC whole-blood concentrations, TAC intracellular concentrations and TAC-induced intracellular calcineurin inhibition.

In this context, the aim of the present study was to explore this relationship in $10 \mathrm{de}$ novo liver transplant recipients treated with TAC at day 1 and day 7 after graft implantation and investigate if these assays can be conducted on a routine mode. 


\section{Materials and Methods:}

\subsection{Patients and data collection:}

Ten de novo liver transplant recipients (nine men and one woman) were included in the present study. Seven patients were transplanted because of alcoholic cirrhosis, two patients because of alcoholic and metabolic cirrhosis and one patient because of alcoholic cirrhosis and hepatocellular carcinoma. All patients were involved in the clinical trial "Pharmacogenetic study of tacrolimus in hepatic transplant (CYPTAC'H)" (Clinicaltrials.gov identifier: NCT01388387). Caucasian patients over 18 years of age treated with TAC and who gave their written consent were included in the study. The investigational review board "Comité de Protection des Personnes - Ouest V" approved the study protocol; all patients provided written informed consent and approved the sampling and pharmacokinetic/pharmacodynamic analysis in compliance with the ethical principles of the revised Declaration of Helsinki (2008) and with French regulations. Patients with highly active antiretroviral therapy or with legal guardianship or deprived of freedom were not eligible for the study.

TAC dose, haematocrit, serum protein, albumin, creatinine, total and conjugated bilirubin, AST, ALT and ALP and creatinine clearance were collected or calculated on the day of blood sampling.

Patients were monitored for the first 6 months after transplantation with particular attention given to the occurrence of acute rejection.

\subsection{Immunosuppression protocol:}

TAC treatment was started either at 8:00 AM or 8:00 PM, depending on the time the surgical procedure was completed. The day of the first administration determined the first day of the study. Patients received initially a dose of 0.04 to $0.05 \mathrm{mg} / \mathrm{kg}$ per 
$12 \mathrm{hrs}$ calculated based on the ideal body weight or a dose of 0.02 to $0.03 \mathrm{mg} / \mathrm{kg}$ per $12 \mathrm{hrs}$ calculated based on ideal body weight in case of concomitant administration of fluconazole prophylaxis. The subsequent doses were adapted to maintain trough TAC whole-blood concentrations between 6 and $10 \mathrm{ng} / \mathrm{mL}$, as recently suggested [20]. From day 1 post-transplantation, patients concomitantly received oral mycophenolate mofetil $1.5 \mathrm{~g}$ twice daily and $20 \mathrm{mg}$ of prednisone once daily. They also received a $500 \mathrm{mg}$ methylprednisolone infusion as an induction and one other $500 \mathrm{mg}$ infusion at portal vein clamp removal.

\subsection{Blood sampling and cell separation}

On their first day of treatment and between the seventh and the tenth day of treatment, each patient underwent complete TAC pharmacokinetics. Five millilitres of peripheral venous blood were collected in EDTA tubes 0, 20, 40, 60, 120, 180, 240, 360,540 and 720 minutes after the morning oral dose of TAC (Prograf ${ }^{\circledR}$ ). Samples were stored at $4^{\circ} \mathrm{C}$ until cells were separated. According to the literature, blood samples could be stored at $4^{\circ} \mathrm{C}$ up to 48 hours after the blood collection [21]. Cell separation was achieved using a Unisep U-02 device for density gradient separation of PBMC provided by NovamedC (Jerusalem, Israel) according to previously published procedures [22]. Blood was diluted with RPMI-glutamate (v/v) (Novamed@, Jerusalem, Israel), then centrifuged at $1200 \mathrm{G}$ (without brake) during 20 minutes at room temperature (RT). The cell layer was collected with a pipette, washed twice with RPMI-glutamate and then centrifuged at $250 \mathrm{G}$ during 10 minutes at $4^{\circ} \mathrm{C}$. The washing procedure was performed twice. Cell counting was performed on a FC500 (Beckman Coulter, Pasadena, CA, USA) according to previously published works $[23,24]$. Briefly, $50 \mu \mathrm{L}$ of cells were incubated with $10 \mu \mathrm{L}$ of CytoDiff@ antibody 
cocktail (Beckman Coulter) at RT during 15 min. Then, $500 \mu \mathrm{L}$ of the "fix-and-lyse" mix (Versalyse + IOTest3, Beckman Coulter, Pasadena, CA, USA) were added and the sample was incubated at RT during 15 minutes. Finally, $50 \mu \mathrm{L}$ of flowcount beads (Beckman Coulter, Pasadena, CA, USA) were added to calibrate the count.

Because of granulocyte contamination during cell separation, all analyses were expressed for 1 million white blood cells. High contamination by granulocytes has already been described in intensive care unit patients with sepsis phase as well as in autoimmune diseases such as systemic lupus erythematosus [25]'[26]. The cell pellet

was then split in aliquots $\left(5 \times 10^{5}\right.$ cells each) dedicated to intracellular TAC concentration and calcineurin activity assays.

\subsection{Assessment of whole blood and intracellular TAC concentrations}

TAC was measured in whole blood using a validated liquid chromatography tandem mass spectrometry (LC-MS/MS) method. The accuracy of our method was ensured by participation in the Tacrolimus Proficiency Testing Scheme provided by the Cardiac and Vascular Sciences Analytic Unit of St. George's Hospital Medical School (D. Holt, London, United Kingdom).

Intracellular TAC concentration was assayed using a validated LC-MS/MS method adapted from previously published methods [22,27]. The intra-day coefficients of variation for TAC controls (50 and 200 pg/million PBMCs) were respectively 8.6 and $9.0 \%$. Coefficients of variation of inter-day analysis of TAC controls (50 and 200 pg/million PBMC) were respectively 2.8 and $8.8 \%$.

\subsection{Calcineurin activity assay}


Calcineurin activity was determined by using high-performance liquid chromatography with ultra-violet detection as previously described [21]. The peptide used, D-L-D-V-P-I-P-G-R-F-D-R-R-V-S-V-A-A-E, is a partial sequence corresponding to the RII subunit of cAMP-dependent protein kinase. The protein phosphatase $2 \mathrm{~B}$ (PP2B) substrate was obtained from Bachem (Bubendorf, Switzerland, >98\% purity). Briefly, cells were resuspended in $20 \mu$ l of lysis buffer $(1 \mathrm{M}$ Tris- $\mathrm{HCl}, \mathrm{pH} 8.0,1 \mathrm{M} \mathrm{KCl}$, Nomidet 40 and tween 20). After a freeze-thaw cycle, lysates were mixed with analysis buffer (50 mM Tris- $\mathrm{HCl}, \mathrm{pH}$ 7.0, 0.1 M EGTA, $0.5 \mathrm{mM}$ dithiothreitol, $1 \mathrm{mM}$ $\mathrm{MnCl}_{2}, 0.3 \mathrm{mg} / \mathrm{mL}$ bovine serum albumin, $0.1 \mathrm{mM}$ EGTA, $1 \mathrm{mM} \mathrm{CaCl}, 0.1 \mu \mathrm{M}$ calmodulin, $500 \mathrm{nM}$ okadaic acid). After sample incubation (15 minutes, $\left.30^{\circ} \mathrm{C}\right)$, the reaction was initiated with the addition of phosphorylated peptides. Aliquots $(50 \mu \mathrm{l})$ were sampled at 5 and 10 minutes, and the enzymatic reaction was stopped with 20 $\mu \mathrm{L}$ of perchloric acid $0.5 \%$. A $50 \mu \mathrm{L}$ aliquot was injected into the chromatographic system. Calcineurin activity was expressed as picomoles of dephosphorylated peptides per minute per $10^{6}$ cells. The intra-day coefficients of variation for quality control for calcineurin activity (1428 and $2856 \mathrm{pmol})$ were respectively 1.0 and $2.1 \%$. Accuracy was shown to be good with an average percentage of less than $98.4 \%$ (range 96.7-104.5) for the two quality controls. During the validation of analytical method, the method showed a good within-day precision $(\mathrm{CV}=13.3 \%)$ including all the steps from blood collection to CNA activity assay by using liquid chromatography [21].

\subsection{Statistical analysis}

The demographic and biological characteristics of the study cohort are presented as mean +/- standard deviation (SD). Creatinine clearance was estimated using the 
Modification of Diet in Renal Disease formula [28]. The results of pharmacokinetic and pharmacodynamic data are expressed as mean $+/$ - standard error of the mean (SEM). Individual area under the whole blood or intracellular TAC concentration-time curve from 0 to 12 hours $\left(\mathrm{AUC}_{0-12}\right)$ was calculated according to the trapezoidal formula. This latter was also used to determine $A U C_{0-12}$ for calcineurin activity $\left(A \cup C_{0-}\right.$ 12CNA). The ratio TAC intracellular $A U C_{0-12}$ over TAC whole-blood $A U C_{0-12}$ on day 1 and day 7 was calculated for each patient assuming that mean cell volume was 200 femtoliters $[29,30]$. Using a mean volume of 200 femtoliters allows us to compare data in blood and within cells on a mass/volume point of view even if it imprecisely reflects the exact volume of the different population cells.

Changes in $\mathrm{AUC}_{0-12 \mathrm{CNA}}$ between day 1 and day 7 were also calculated for each patient by dividing the value of $A U C_{0-12 C N A}$ on day 7 by the value of $A U C_{0-12 C N A}$ on day 1. Whole blood, intracellular and calcineurin activity AUCs were compared between day 1 and day 7 using a paired Wilcoxon test.

The relationships between TAC whole-blood $A \cup C_{0-12}$, TAC intracellular $A \cup C_{0-12}$ and $\mathrm{AUC}_{0-12 \mathrm{CNA}}$ were tested out using the Spearman correlation test.

All tests were two-sided, and they were considered significant when p-values were < 0.05. Computations were performed using the SAS V9 statistical package (SAS institute, Cary, NC).

\section{Results:}

\subsection{Patients' characteristics}

Table 1 presents the baseline demographic and clinical data of the 10 de novo liver transplant recipients included in the study. Biological parameters of patients at day 1 and day 7 after graft implantation are summarized in Table 2. 


\subsection{TAC blood and intracellular pharmacokinetics}

Pharmacokinetic parameters for TAC at day 1 and day 7 after graft implantation are summarized in Table 3. In whole blood, TAC maximum concentration $\left(\mathrm{C}_{\max }\right)$ reached $13.0 \pm 9.6 \mathrm{ng} / \mathrm{mL}$ at 180 minutes on day 1 and $8.8 \pm 5.0 \mathrm{ng} / \mathrm{mL}$ at 60 minutes on day 7 (Figure 1). TAC trough concentrations $\left(\mathrm{C}_{12 \mathrm{~h}}\right)$ were $6.9 \pm 3.1 \mathrm{ng} / \mathrm{mL}$ and $5.4 \pm 3.1$ $\mathrm{ng} / \mathrm{mL}$ on day 1 and day 7 respectively. Corresponding areas under the curve over the administration period $\left(\mathrm{AUC}_{0-12}\right)$ were $111.8 \pm 65.9 \mathrm{ng} \cdot \mathrm{h} / \mathrm{mL}$ and $81.2 \pm 37.2$ ng.h/mL, respectively.

For intracellular pharmacokinetics, mean $C_{\max }$ reached $116.9 \pm 114.7 \mathrm{pg} /$ million leukocytes at 180 minutes on day 1 and $68.3 \pm 48.9 \mathrm{pg} /$ million leukocytes at 360 minutes on day 7 (Figure 2). $\mathrm{C}_{12 \mathrm{~h}}$ were $71.3 \pm 78.5$ and $39.5 \pm 38.8 \mathrm{pg} / \mathrm{million}$ leukocytes at day 1 and 7, respectively. $\mathrm{AUC}_{0-12}$ were $909.2 \pm 903.7 \mathrm{pg} . \mathrm{h} / \mathrm{million}$ leukocytes and $673.0 \pm 603.0 \mathrm{pg}$. h/million leukocytes.

The ratio TAC intracellular $A \cup C_{0-12}$ over TAC whole-blood $A \cup C_{0-12}$ presented a large variability at day 1 (5.2 to 70 , mean $40.3 \pm 23.3$ ) and day 7 (8.0 to 114.8 , mean 49.3 $\pm 23.3)$

\subsection{TAC pharmacodynamics}

Figure 3 presents the time course of calcineurin activity in leukocytes at day 1 and day 7 after transplantation. At day 1 , calcineurin activity changed in parallel with both whole blood and intracellular TAC concentrations. Thus, the time to achieve the mean maximum calcineurin inhibition ( $38 \pm 16 \%$ ) was close to that for maximum TAC whole blood and intracellular concentrations. At day 7 , the mean calcineurin activity over the dosing interval was unchanged, within $+/-15 \%$. 
Mean $\mathrm{AUC}_{0-12 \mathrm{CNA}}$ at day 1 and day 7 were not statistically different $\left(\mathrm{AUC}_{0-12 \mathrm{CNA}}=\right.$ $404.2 \pm 251.1$ vs $472.8 \pm 382.9 \mathrm{pmol} / \mathrm{min} / 10^{6}$ leukocytes, respectively; $\mathrm{p}=0.95$ ) Overall, mean variation in $\mathrm{AUC}_{0-12 \mathrm{CNA}}$ between day 1 and day 7 was $1.17 \pm 0.65$.

\subsection{PK-PD relationship}

A correlation between the whole blood TAC $\mathrm{AUC}_{0-12}$ and the intracellular TAC $A U C_{0-}$ 12 was observed at day $1($ rho $=0.69 ; p=0.04)$ but not at day $7(p=0.75)$ (Figure 4). No correlation was found between whole blood TAC $A U C_{0-12}$ and $\mathrm{AUC}_{0-12 \mathrm{CNA}}$ at day 1 $(p=0.92)$ and day $7(p=0.10)$ either between intracellular TAC AUC $C_{0-12}$ and $A \mathrm{AC}_{0-}$ $12 \mathrm{CNA}$ at day $1(p=0.71)$ and day $7(p=0.88)$ (Figure 5$)$.

No difference could be found between day 1 and day 7 in whole blood $A \mathrm{C}_{0-12}(p=$ $0.25)$, intracellular $\mathrm{AUC}_{0-12}(p=0.38)$, TAC diffusion ratio into leukocytes $(p=1.00)$, or $\mathrm{AUC}_{0-12 \mathrm{CNA}}(\mathrm{p}=0.74)$.

\subsection{Clinical outcome}

One patient experienced an ACR during the study. The onset of this acute rejection was 17 days after the surgical procedure. This patient had TAC whole-blood $\mathrm{AUC}_{0-12}$ at day 1 and day $7(81.3 \mathrm{ng} . \mathrm{h} / \mathrm{mL}$ and $70.0 \mathrm{ng} \cdot \mathrm{h} / \mathrm{mL}$, respectively) close to the mean of the patient study on day 7. In contrast, his intracellular TAC $A U C_{0-12}$ at day 1 and day 7 (186.2 pg.h/million leukocytes and $112.2 \mathrm{pg} . \mathrm{h} / \mathrm{million}$ leukocytes, respectively) was approximately 4-fold lower than the mean $\mathrm{AUC}_{0-12}$ of the other patients. He also presented the lowest ratio TAC intracellular $\mathrm{AUC}_{0-12}$ over TAC whole-blood $\mathrm{AUC}_{0-12}$ at day 7 (8.0, study mean $49.3 \pm 45.6)$. Finally, his $A U_{0-12 C N A}$ significantly increased from $90.7 \mathrm{pmol} / \mathrm{min} / 10^{6}$ leukocytes at day 1 to $189.5 \mathrm{pmol} / \mathrm{min} / 10^{6}$ leukocytes at day 7. The change in $\mathrm{AUC}_{0-12 \mathrm{CNA}}$ between day 1 and day 7 was 2.09 for this patient 
(mean change for all patients was $1.17 \pm 0.65$ ), that was the largest increase in the patient study.

\section{Discussion:}

Different investigations carried out in liver transplant recipients have already investigated the relationship between TAC whole blood concentrations and calcineurin activity in PBMC $[16,17,31-33]$ or between concentrations of TAC in whole blood and PBMC [10,14,34]. To our best knowledge, the present study is the first to study both the pharmacokinetics of TAC in whole blood and leukocytes as well as the TAC-induced effect on calcineurin activity in leukocytes. On the 10 patients included in this study, we did not evidence any relation between TAC pharmacokinetics (whole blood and leukocytes) and calcineurin activity in leukocytes at day 1 and day 7 after the graft implantation.

Capron et al. have recently documented that low TAC concentration in PBMC within the first 7 treatment days was associated with the occurrence of ACR in 90 liver transplant recipients treated with TAC [10]. However, Capron patients were treated with TAC alone whereas our patients received a combination of 3 immunosuppressive drugs. Different investigations have reported that liver transplant recipients experiencing $A C R$ exhibit higher calcineurin activity than those without a rejection episode, suggesting a lower pharmacological impact of TAC [16-18]. This increased calcineurin activity within a graft rejection episode has also been confirmed in patients after lung [35], renal [36] or liver transplantation [18]. The question raised 
by these studies is: does a low TAC intracellular concentration leading to an insufficient inhibition of calcineurin activity may result in the development of ACR ?.

In accordance with Blanchet et al. [31], the present study failed to find any relationship between TAC whole blood pharmacokinetics and calcineurin activity at day 7 after liver graft implantation. Interestingly, we show for the first time that TAC intracellular exposure was not better correlated with calcineurin activity than TAC whole blood exposure. Different reasons can explain this result. Firstly, the interindividual variability in calcineurin activity was very large because of both analytical reasons [37] and aetiology of liver transplantation [32]. Secondly, the profile of calcineurin activity was relatively flat at day 7 , probably because our patients were exposed to low TAC whole blood concentrations (mean trough concentration $5.4 \pm 3.1 \mathrm{ng} / \mathrm{mL}$ ). At saturating TAC concentrations, several in vitro studies [38,39] have documented a maximal calcineurin inhibition around $50 \%$ for tacrolimus-naïve PBMC. This incomplete inhibition of calcineurin activity is related to a limited FK Binding Protein 12 amount in cytoplasm [39]. The level of expression of other protein, such as FK Binding Protein 13 and FK Binding Protein 25, which binds TAC without inhibiting calcineurin activity, might also contributed to the variability in calcineurin inhibition in PBMCs [40]. In this context, a high intracellular expression of these protein in PBMC could contribute to a lower tacrolimus-induced calcineurin inhibition. In liver transplant recipients, Fukudo et al. estimated an $\mathrm{EC}_{50}$ (TAC whole blood concentration which decreases maximal calcineurin activity by a half) of 26.4 $\mathrm{ng} / \mathrm{mL}$ related to the large diffusion of TAC in erythrocytes [17]. This value of $\mathrm{EC}_{50}$ is approximately three-fold higher than the mean TAC whole blood $\mathrm{C}_{\max }$ at day 7 observed in the present study, which explains in part the modest calcineurin inhibition observed over the dosing interval in our study. Thirdly, in contrast with day 7, a 
significant inhibition of calcineurin activity was observed over the dosing interval at day 1 with a nadir 4 hours after TAC intake which corresponds roughly to the wholeblood and intracellular $\mathrm{C}_{\max }$.

The interest of the present study also implemented pharmacokinetic and pharmacodynamic data in liver transplant recipients exposed to low trough TAC whole blood concentrations (target range: $6-10 \mathrm{ng} / \mathrm{mL}$ ). Indeed, a recent metaanalysis emphasizes the fact that TAC whole blood trough concentrations maintained between 6 and $10 \mathrm{ng} / \mathrm{mL}$ in liver transplant recipients during the first month of treatment do not lead to a higher rate of $A C R$ when compared with patients in whom trough concentrations were between 10 and $15 \mathrm{ng} / \mathrm{mL}$ [20]. In the present study, baseline calcineurin activity (activity just before the first administration of TAC) and trough calcineurin activity at day 7 were not statistically different $(655 \pm 401$ vs 621 $\pm 469 \mathrm{pmol} / \mathrm{min} / 10^{6}$ leukocytes, $\left.\mathrm{p}=0.11\right)$. Additionally, only one patient experienced a histological ACR episode during the 6-month follow-up (Banff score $=4$ ). Although the number of patients included in our study is limited, these results suggest that a lack of significant inhibition of calcineurin activity might not cause acute rejection when immune systems are suppressed by other drugs such as mycophenolic acid and glucocorticoids. Capron et al. have reported a rate of histological ACR around $40 \%$ when TAC is used in monotherapy (target blood concentrations of around 6 $\mathrm{ng} / \mathrm{mL}$ ) [10]. This result associated with ours suggests that a low CNA inhibition should be only targeted when TAC is used in combination with other immunosuppressive agents such as mycophenolate mofetil and glucocorticoid. However, given that $80 \%$ of our patients were transplanted for alcoholic cirrhosis, the present results are more specific to these patients which frequently exhibited lower 
pre-transplantation CNA activity that those observed for other liver aetiologies such as viral cirrhosis, autoimmune liver disease [32]. Further investigations with a larger cohort including non-alcoholic patients are required to address this issue. Also, further pharmacodynamic investigations are necessary to confirm the weak calcineurin inhibition at the target range $6-10 \mathrm{ng} / \mathrm{mL}$ and its impact on the incidence of $A C R$.

Interestingly, the single patient who experienced ACR during the 6-month follow-up exhibited the highest increase in calcineurin activity between day 1 and day 7 . Despite a good TAC whole blood exposure, this patient had the lowest TAC exposure in leukocytes at steady-state because of a very low TAC intracellular ratio, which was approximately 6-fold lower than the mean TAC intracellular ratio for the patient cohort. In accordance with the work of Capron et al. [10], this episode of ACR suggests that monitoring TAC concentration in PBMC may be helpful during the first week of treatment to identify patients in whom the TAC intracellular concentration is low and therefore the risk of ACR is high. Although this approach seems easier than the monitoring of calcineurin activity in daily clinical practice, it cannot take account for intracellular factors which can influence calcineurin activity despite a satisfying TAC intracellular exposure. These intracellular factors include among others a low amount of FK Binding Protein 12 and/or a high amount of FK Binding Protein 13 and FK Binding Protein 25 which can bind to TAC without mediating the inhibitory effect of TAC on calcineurin [40]. Therefore, monitoring CNA activity would be more relevant in daily clinical practice; however one limiting factor to its use is the large variability in analytical method related to different factors such as difference in PBMC sample composition and loss CNA activity due to fractionizing and separation 
procedures [37]. In this context, the most powerful and useful tool, between intracellular TAC measurement and calcineurin activity monitoring, to identify likely non-responders to TAC therapy has yet to be evaluated.

\section{Conclusion:}

Drug monitoring of TAC intracellular concentrations and determination of the calcineurin activity are among future potential biomarkers of acute rejection in transplant recipients. A better knowledge of the relationship between TAC whole blood and intracellular concentrations and calcineurin activity appears necessary before planning clinical trials to evaluate their potential interest as predictive biomarkers. The present work highlights new data in liver transplant recipients, in particular complete 12-hour pharmacokinetics of intracellular TAC concentrations as well as complete profiles of calcineurin activity. 


\section{Figure legends:}

Figure 1. Mean whole blood tacrolimus concentrations over a 12-hour period in 10 liver transplant recipients at day-1 (diamonds) and day-7 (squares) after graft implantation. Results are expressed as means $+/$ - standard error of the mean.

Figure 2. Mean intracellular tacrolimus concentration over a 12-hour period in leukocytes from 10 liver transplant recipients at day-1 (diamonds) and day-7 (squares) after graft implantation. Results are expressed as means $+/$ - standard error of the mean.

Figure 3. Mean calcineurin activity over a 12-hour period in leukocytes from 10 liver transplant recipients at day-1 (diamonds) and day-7 (squares) after graft implantation. Results are expressed as means $+/$ - standard error of the mean.

Figure 4. Mean whole blood tacrolimus concentrations versus mean intracellular tacrolimus concentrations at day-1 (diamonds) and day-7 (squares) after graft implantation.

Figure 5. Mean calcineurin activity versus mean intracellular tacrolimus concentrations at day-1 (diamonds) and day-7 (squares) after graft implantation. 


\section{Acknowledgements:}

Grants, financial support and conflict of interest: FL has received a research grant from Astellas Pharma and has received funding to attend meetings and conferences; CC has received funding to attend meetings and conferences from Astellas Pharma ; PHD and KB has received funding to attend meetings and conferences and speaker fees from Astellas Pharma. All other authors have no conflict of interest to declare. 


\section{References:}

[1] Staatz CE, Tett SE. Clinical pharmacokinetics and pharmacodynamics of tacrolimus in solid organ transplantation. Clin Pharmacokinet 2004;43:623-53.

[2] Wallemacq P, Armstrong VW, Brunet M, Haufroid V, Holt DW, Johnston A, et al. Opportunities to optimize tacrolimus therapy in solid organ transplantation: report of the European consensus conference. Ther Drug Monit 2009;31:139-52. doi:10.1097/FTD.0b013e318198d092.

[3] Boudjema K, Camus C, Saliba F, Calmus Y, Salamé E, Pageaux G, et al. Reduced-dose tacrolimus with mycophenolate mofetil vs. standard-dose tacrolimus in liver transplantation: a randomized study. Am J Transplant Off J Am Soc Transplant Am Soc Transpl Surg 2011;11:965-76. doi:10.1111/j.1600-6143.2011.03486.x.

[4] Thervet E, Loriot MA, Barbier S, Buchler M, Ficheux M, Choukroun G, et al. Optimization of initial tacrolimus dose using pharmacogenetic testing. Clin Pharmacol Ther 2010;87:721-6. doi:10.1038/clpt.2010.17.

[5] Antignac M, Fernandez C, Barrou B, Roca M, Favrat J-L, Urien S, et al. Prediction tacrolimus blood levels based on the Bayesian method in adult kidney transplant patients. Eur J Drug Metab Pharmacokinet 2011;36:25-33.

doi:10.1007/s13318-011-0027-z.

[6] Staatz CE, Willis C, Taylor PJ, Lynch SV, Tett SE. Toward better outcomes with tacrolimus therapy: population pharmacokinetics and individualized dosage prediction in adult liver transplantation. Liver Transplant Off Publ Am Assoc Study Liver Dis Int Liver Transplant Soc 2003;9:130-7. doi:10.1053/jlts.2003.50023.

[7] Gérard C, Stocco J, Hulin A, Blanchet B, Verstuyft C, Durand F, et al. Determination of the Most Influential Sources of Variability in Tacrolimus Trough Blood Concentrations in Adult Liver Transplant Recipients: A Bottom-Up Approach. AAPS J 2014. doi:10.1208/s12248-014-9577-8.

[8] Van Gelder T, Hesselink DA. Dosing tacrolimus based on CYP3A5 genotype: will it improve clinical outcome? Clin Pharmacol Ther 2010;87:640-1. doi:10.1038/clpt.2010.42.

[9] Kuypers DRJ. Pharmacogenetic vs. concentration-controlled optimization of tacrolimus dosing in renal allograft recipients. Clin Pharmacol Ther 2010;88:595-596; author reply 597. doi:10.1038/clpt.2010.129.

[10] Capron A, Lerut J, Latinne D, Rahier J, Haufroid V, Wallemacq P. Correlation of tacrolimus levels in peripheral blood mononuclear cells with histological staging of rejection after liver transplantation: preliminary results of a prospective study. Transpl Int Off J Eur Soc Organ Transplant 2012;25:41-7. doi:10.1111/j.1432-

2277.2011.01365.x.

[11] Lemaitre F, Antignac M, Verdier M-C, Bellissant E, Fernandez C. Opportunity to monitor immunosuppressive drugs in peripheral blood mononuclear cells: Where are we and where are we going? Pharmacol Res Off J Ital Pharmacol Soc 2013;74C:109-12. doi:10.1016/j.phrs.2013.06.003.

[12] Zahir H, McCaughan G, Gleeson M, Nand RA, McLachlan AJ. Changes in tacrolimus distribution in blood and plasma protein binding following liver transplantation. Ther Drug Monit 2004;26:506-15.

[13] Pauli-Magnus C, Kroetz DL. Functional implications of genetic polymorphisms in the multidrug resistance gene MDR1 (ABCB1). Pharm Res 2004;21:904-13.

[14] Capron A, Mourad M, De Meyer M, De Pauw L, Eddour DC, Latinne D, et al. CYP3A5 and ABCB1 polymorphisms influence tacrolimus concentrations in 
peripheral blood mononuclear cells after renal transplantation. Pharmacogenomics 2010;11:703-14. doi:10.2217/pgs.10.43.

[15] Yano I. Pharmacodynamic monitoring of calcineurin phosphatase activity in transplant patients treated with calcineurin inhibitors. Drug Metab Pharmacokinet 2008;23:150-7.

[16] Fukudo M, Yano I, Katsura T, Ito N, Yamamoto S, Kamoto T, et al. A transient increase of calcineurin phosphatase activity in living-donor kidney transplant recipients with acute rejection. Drug Metab Pharmacokinet 2010;25:411-7. [17] Fukudo M, Yano I, Masuda S, Fukatsu S, Katsura T, Ogura Y, et al. Pharmacodynamic analysis of tacrolimus and cyclosporine in living-donor liver transplant patients. Clin Pharmacol Ther 2005;78:168-81. doi:10.1016/j.clpt.2005.04.008.

[18] Boleslawski E, Conti F, Sanquer S, Podevin P, Chouzenoux S, Batteux F, et al. Defective inhibition of peripheral CD8+ T cell IL-2 production by anti-calcineurin drugs during acute liver allograft rejection. Transplantation 2004;77:1815-20.

[19] Van Rossum HH, de Fijter JW, van Pelt J. Pharmacodynamic monitoring of calcineurin inhibition therapy: principles, performance, and perspectives. Ther Drug Monit 2010;32:3-10. doi:10.1097/FTD.0b013e3181c0eecb.

[20] Rodríguez-Perálvarez M, Germani G, Darius T, Lerut J, Tsochatzis E, Burroughs AK. Tacrolimus trough levels, rejection and renal impairment in liver transplantation: a systematic review and meta-analysis. Am J Transplant Off J Am Soc Transplant Am Soc Transpl Surg 2012;12:2797-814. doi:10.1111/j.16006143.2012.04140.x.

[21] Blanchet B, Hulin A, Duvoux C, Astier A. Determination of serine/threonine protein phosphatase type 2B PP2B in lymphocytes by HPLC. Anal Biochem 2003;312:1-6.

[22] Lemaitre F, Antignac M, Fernandez C. Monitoring of tacrolimus concentrations in peripheral blood mononuclear cells: Application to cardiac transplant recipients. Clin Biochem 2013. doi:10.1016/j.clinbiochem.2013.02.011. [23] Roussel M, Benard C, Ly-Sunnaram B, Fest T. Refining the white blood cell differential: the first flow cytometry routine application. Cytom Part J Int Soc Anal Cytol 2010;77:552-63. doi:10.1002/cyto.a.20893.

[24] Gac F, Thibert JB, Le Berre C, Le Priol J, Semana G, Fest T, et al. Evaluation of CytoDiff ${ }^{\mathrm{TM}}$ on cord blood WBC differential. Int J Lab Hematol 2013;35:46-54. doi:10.1111/j.1751-553X.2012.01460.x.

[25] Van den Akker ELT, Baan CC, van den Berg B, Russcher H, Joosten K, Hokken-Koelega ACS, et al. Ficoll-separated mononuclear cells from sepsis patients are contaminated with granulocytes. Intensive Care Med 2008;34:912-6. doi:10.1007/s00134-007-0989-0.

[26] Kaplan MJ. Neutrophils in the pathogenesis and manifestations of SLE. Nat Rev Rheumatol 2011;7:691-9. doi:10.1038/nrrheum.2011.132.

[27] Roullet-Renoleau F, Lemaitre F, Antignac M, Zahr N, Farinotti R, Fernandez C. Everolimus quantification in peripheral blood mononuclear cells using ultra high performance liquid chromatography tandem mass spectrometry. J Pharm Biomed Anal 2012;66:278-81. doi:10.1016/j.jpba.2012.03.042.

[28] Levey AS, Coresh J, Greene T, Marsh J, Stevens LA, Kusek JW, et al. Expressing the Modification of Diet in Renal Disease Study equation for estimating glomerular filtration rate with standardized serum creatinine values. Clin Chem 2007;53:766-72. doi:10.1373/clinchem.2006.077180. 
[29] Kuse R, Schuster S, Schübbe H, Dix S, Hausmann K. Blood lymphocyte volumes and diameters in patients with chronic lymphocytic leukemia and normal controls. Blut 1985;50:243-8.

[30] Segel GB, Cokelet GR, Lichtman MA. The measurement of lymphocyte volume: importance of reference particle deformability and counting solution tonicity. Blood 1981;57:894-9.

[31] Blanchet B, Duvoux C, Costentin CE, Barrault C, Ghaleh B, Salvat A, et al. Pharmacokinetic-pharmacodynamic assessment of tacrolimus in liver-transplant recipients during the early post-transplantation period. Ther Drug Monit 2008;30:4128. doi:10.1097/FTD.0b013e318178e31b.

[32] Blanchet B, Hurtova M, Roudot-Thoraval F, Costentin CE, Barrault C, Jouault $\mathrm{H}$, et al. Deficiency in calcineurin activity in liver transplantation candidates with alcoholic cirrhosis or hepatocellular carcinoma. Liver Int Off J Int Assoc Study Liver 2009;29:1152-7. doi:10.1111/j.1478-3231.2009.02084.x.

[33] Yano I, Masuda S, Egawa H, Sugimoto M, Fukudo M, Yoshida Y, et al. Significance of trough monitoring for tacrolimus blood concentration and calcineurin activity in adult patients undergoing primary living-donor liver transplantation. Eur J Clin Pharmacol 2012;68:259-66. doi:10.1007/s00228-011-1129-x.

[34] Capron A, Musuamba F, Latinne D, Mourad M, Lerut J, Haufroid V, et al. Validation of a liquid chromatography-mass spectrometric assay for tacrolimus in peripheral blood mononuclear cells. Ther Drug Monit 2009;31:178-86.

doi:10.1097/FTD.0b013e3181905aaa.

[35] Sanquer S, Amrein C, Grenet D, Guillemain R, Philippe B, Boussaud V, et al. Expression of calcineurin activity after lung transplantation: a 2-year follow-up. PloS One 2013;8:e59634. doi:10.1371/journal.pone.0059634.

[36] Brunet M, Crespo M, Millán O, Serón D, Torregrosa V, Jiménez O, et al. Pharmacokinetics and pharmacodynamics in renal transplant recipients under treatment with cyclosporine and Myfortic. Transplant Proc 2007;39:2160-2. doi:10.1016/j.transproceed.2007.07.003.

[37] Van Rossum HH, Romijn FPHTM, Sellar KJ, Smit NPM, van der Boog PJM, de Fijter JW, et al. Variation in leukocyte subset concentrations affects calcineurin activity measurement: implications for pharmacodynamic monitoring strategies. Clin Chem 2008;54:517-24. doi:10.1373/clinchem.2007.097253.

[38] Blanchet B, Hulin A, Ghaleh B, Giraudier S, Jouault H, Astier A. Distribution of calcineurin activity in blood cell fractions and impact of tacrolimus inhibition. Fundam Clin Pharmacol 2006;20:137-44. doi:10.1111/j.1472-8206.2006.00399.x.

[39] Kung L, Halloran PF. Immunophilins may limit calcineurin inhibition by cyclosporine and tacrolimus at high drug concentrations. Transplantation 2000;70:327-35.

[40] Bram RJ, Hung DT, Martin PK, Schreiber SL, Crabtree GR. Identification of the immunophilins capable of mediating inhibition of signal transduction by cyclosporin A and FK506: roles of calcineurin binding and cellular location. Mol Cell Biol 1993;13:4760-9. 
Figure 1.

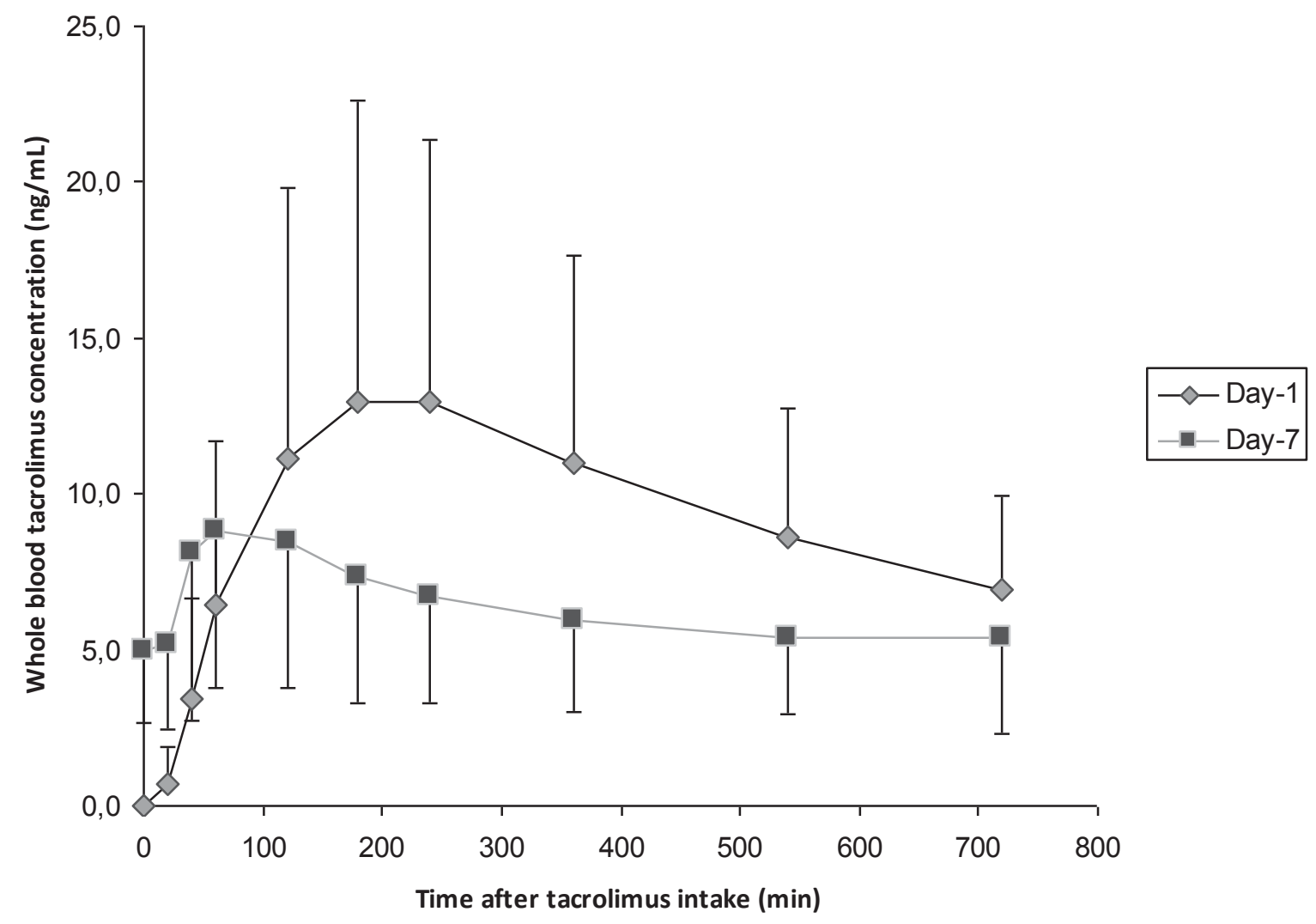


Figure 2.

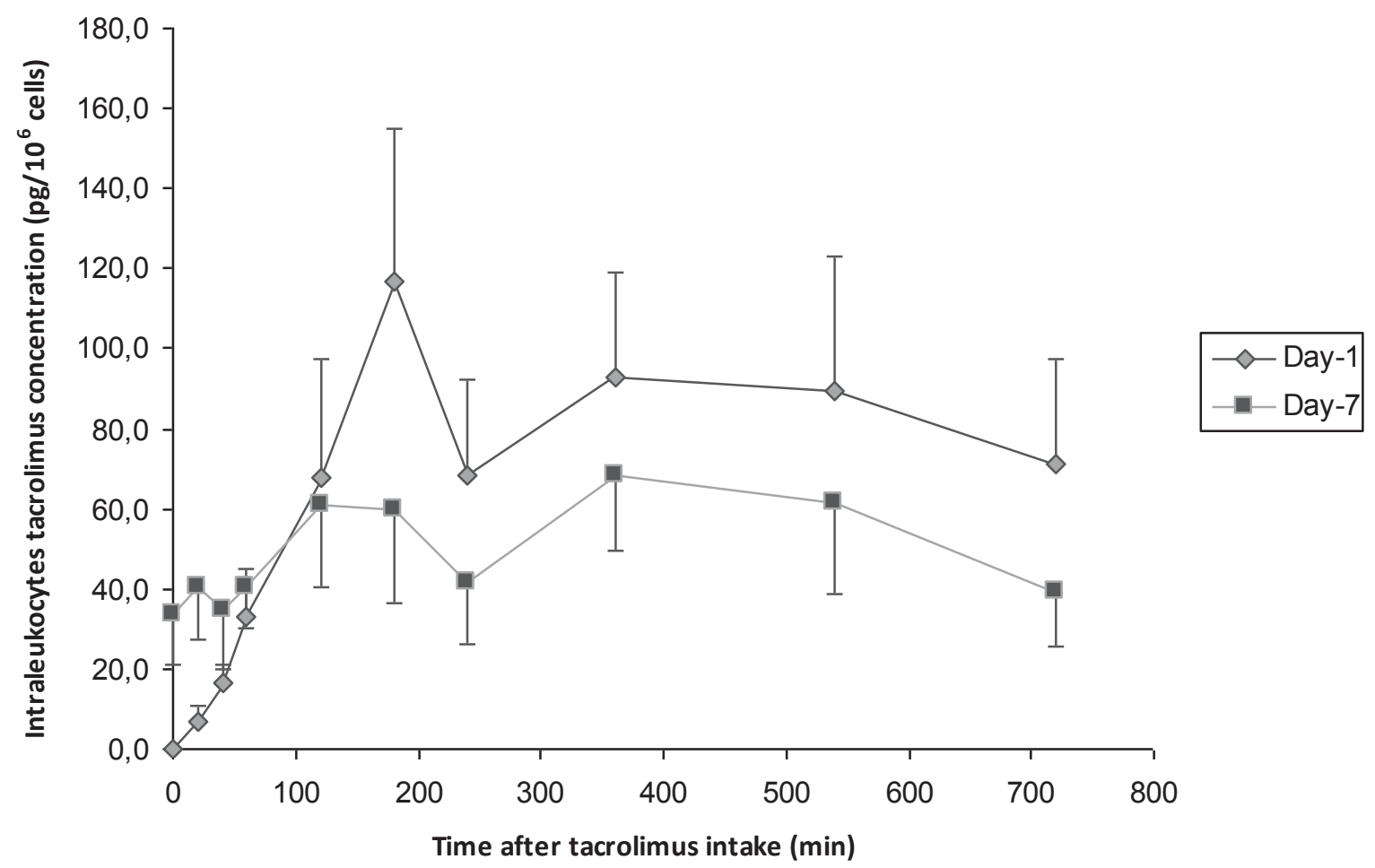


Figure 3.

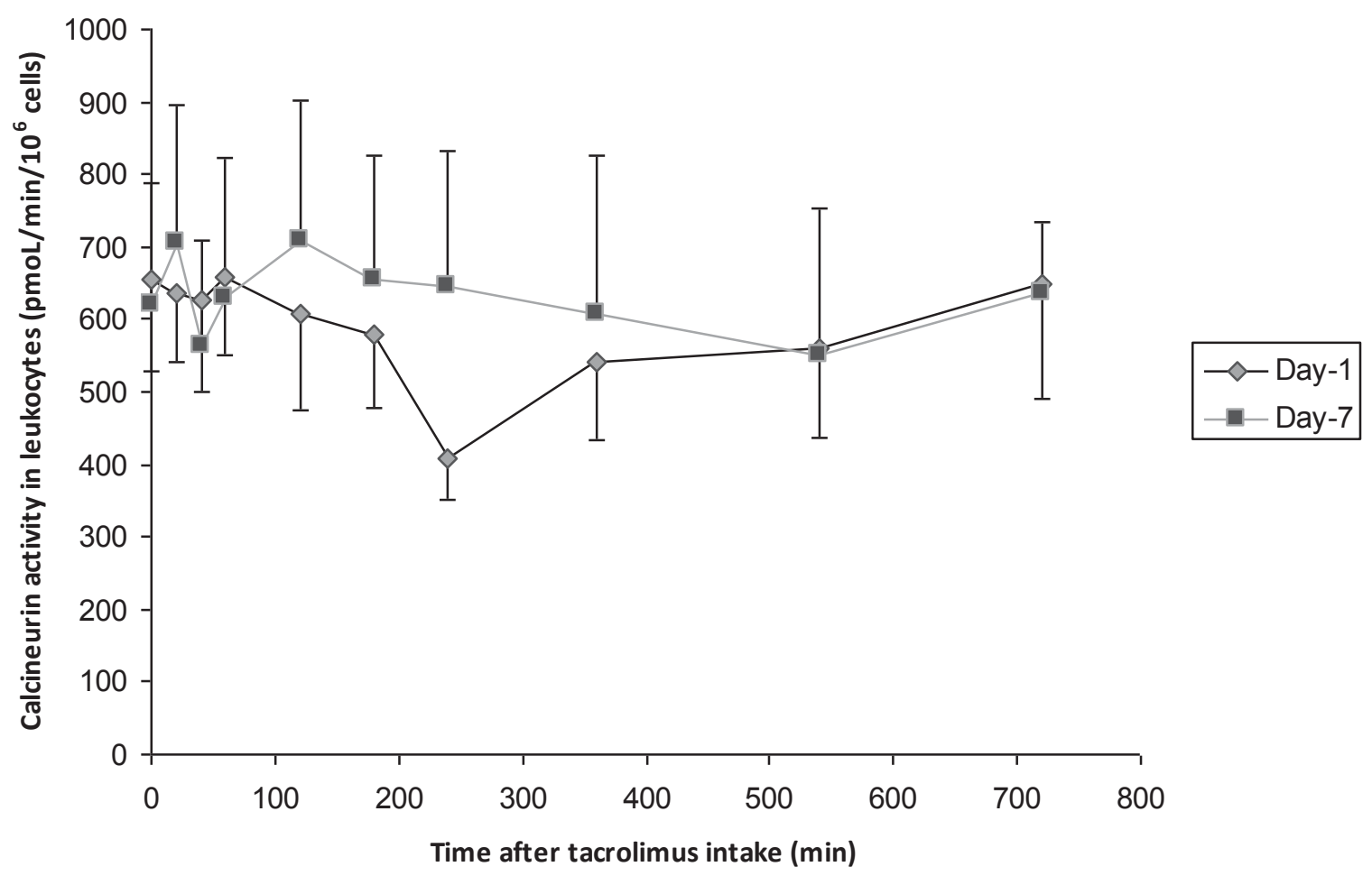


Figure 4.

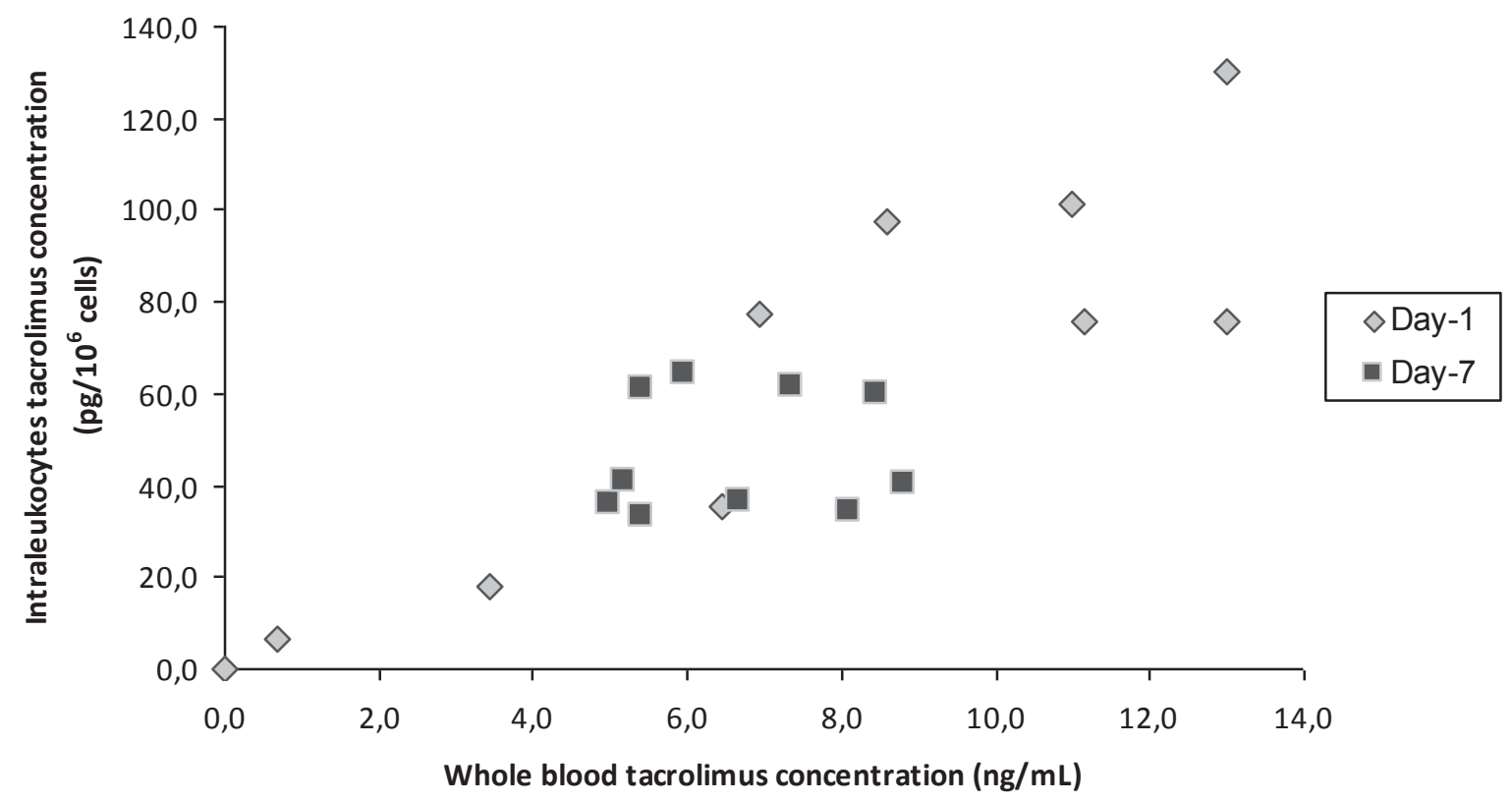


Figure 5.

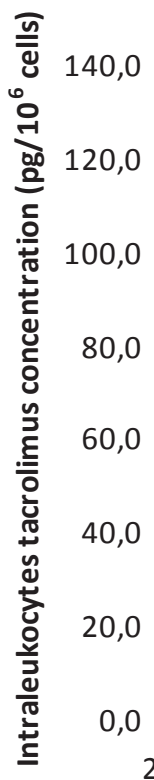

7 20,0

0,0

,

0
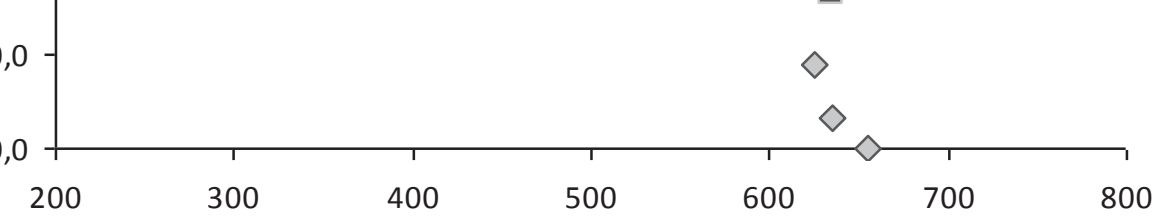

Calcineurin activity in leukocytes ( $\mathrm{pmoL} / \mathrm{min} / 10^{6}$ cells)

$\diamond$ Day-1

- Day-7 
Table 1. Baseline characteristics of the patients.

\begin{tabular}{|l|c|}
\hline & Mean \\
\hline Age (year) & $56.4 \pm 10.9$ \\
\hline Body weight $(\mathrm{kg})$ & $69.4 \pm 16.6$ \\
\hline Cold ischemia (minutes) & $592.4 \pm 230.1$ \\
\hline Graft weight (g) & $1536.0 \pm 482.6$ \\
\hline MELD score & $20.4 \pm 7.7$ \\
\hline
\end{tabular}

Note: Results are expressed as mean \pm SD 
Table 2. Biological parameters of patients at day-1 and day-7 after graft implantation.

\begin{tabular}{|c|c|c|c|}
\hline & day-1 & day-7 & $p$ \\
\hline Hematocrit (\%) & $37.5 \pm 7.9$ & $28.7 \pm 2.9$ & 0.06 \\
\hline Protein $(g / L)$ & $50.7 \pm 8.8$ & $50.9 \pm 8.2$ & 0.36 \\
\hline Albumin (g/L) & $32.4 \pm 8.2$ & $32.7 \pm 2.5$ & 0.94 \\
\hline Total bilirubin $(\mu \mathrm{mol} / \mathrm{L}))$ & $136 \pm 161$ & \pm 126 & 0.96 \\
\hline Conjugated bilirubin $(\mu \mathrm{mol} / \mathrm{L})$ & $67 \pm 74$ & $71 \pm 69$ & 0.80 \\
\hline AST (UI/L) & $1181 \pm 1456$ & $87 \pm 92$ & $0.02^{b}$ \\
\hline ALT (UI/L) & $738 \pm 1021$ & $144 \pm 117$ & $0.04^{b}$ \\
\hline ALP (UI/L) & $07 \pm 31$ & $170.4 \pm 79$ & $0.02^{b}$ \\
\hline Creatinine $(\mu \mathrm{mol} / \mathrm{L})$ & $126 \pm 88$ & $130 \pm 93$ & 0.31 \\
\hline Creatinine clearance $^{a}(\mathrm{~mL} / \mathrm{min})$ & $74.0 \pm 27.1$ & $74.0 \pm 39.1$ & 0.27 \\
\hline
\end{tabular}

Note: ALP: alkaline phosphatase; ALT: Alanine aminotransferase; AST: Aspartate aminotransferase

Results are expressed as mean \pm SD

${ }^{a}$ The creatinine clearance was estimated using the Modification of Diet in Renal Disease (MDRD) formula

${ }^{\mathrm{b}}$ Statistically significant result 
Table 3. Pharmacokinetic parameters for tacrolimus at day-1 and day-7 after graft implantation.

\begin{tabular}{|l|c|c|}
\hline & Day-1 & Day-7 \\
\hline Dose $(\mathrm{mg} / 12 \mathrm{~h})$ & $2.05 \pm 0.93$ & $1.67 \pm 1.12$ \\
\hline Dose per kg (mg/kg.12h) & $0.034 \pm 0.012$ & $0.032 \pm 0.017$ \\
\hline Blood pharmacokinetics & & \\
\hline $\mathrm{C}_{\max }(\mathrm{ng} / \mathrm{mL})$ & $13.0 \pm 9.6$ & $8.8 \pm 5.0$ \\
\hline $\mathrm{C}_{12 \mathrm{~h}}(\mathrm{ng} / \mathrm{mL})$ & $6.9 \pm 3.1$ & $5.4 \pm 3.1$ \\
\hline AUC $_{0-12}(\mathrm{ng} . \mathrm{h} / \mathrm{mL})$ & $111.8 \pm 65.9$ & $81.2 \pm 37.2$ \\
\hline Intracellular pharmacokinetics & & \\
\hline $\mathrm{C}_{\max }(\mathrm{pg} / \mathrm{million}$ leukocytes) & $116.9 \pm 114.7$ & $68.3 \pm 48.9$ \\
\hline $\mathrm{C}_{12 \mathrm{~h}}(\mathrm{pg} / \mathrm{million}$ leukocytes) & $71.3 \pm 78.5$ & $39.5 \pm 38.8$ \\
\hline AUC $\mathrm{C}_{0-12}$ (pg.h/million leukocytes) & $909.2 \pm 903.7$ & $673.0 \pm 602.0$ \\
\hline Intracellular diffusion ratio & & \\
\hline Intracellular AUC & & $49.3 \pm 45.6$ \\
\hline
\end{tabular}

Note: $\mathrm{C}_{\max }$ : maximum concentration over the dosing interval; $\mathrm{C}_{12 \mathrm{~h}}$ : concentration measured 12 hours after tacrolimus intake; AUC $_{0-12}$ : AUC over the dosing interval 


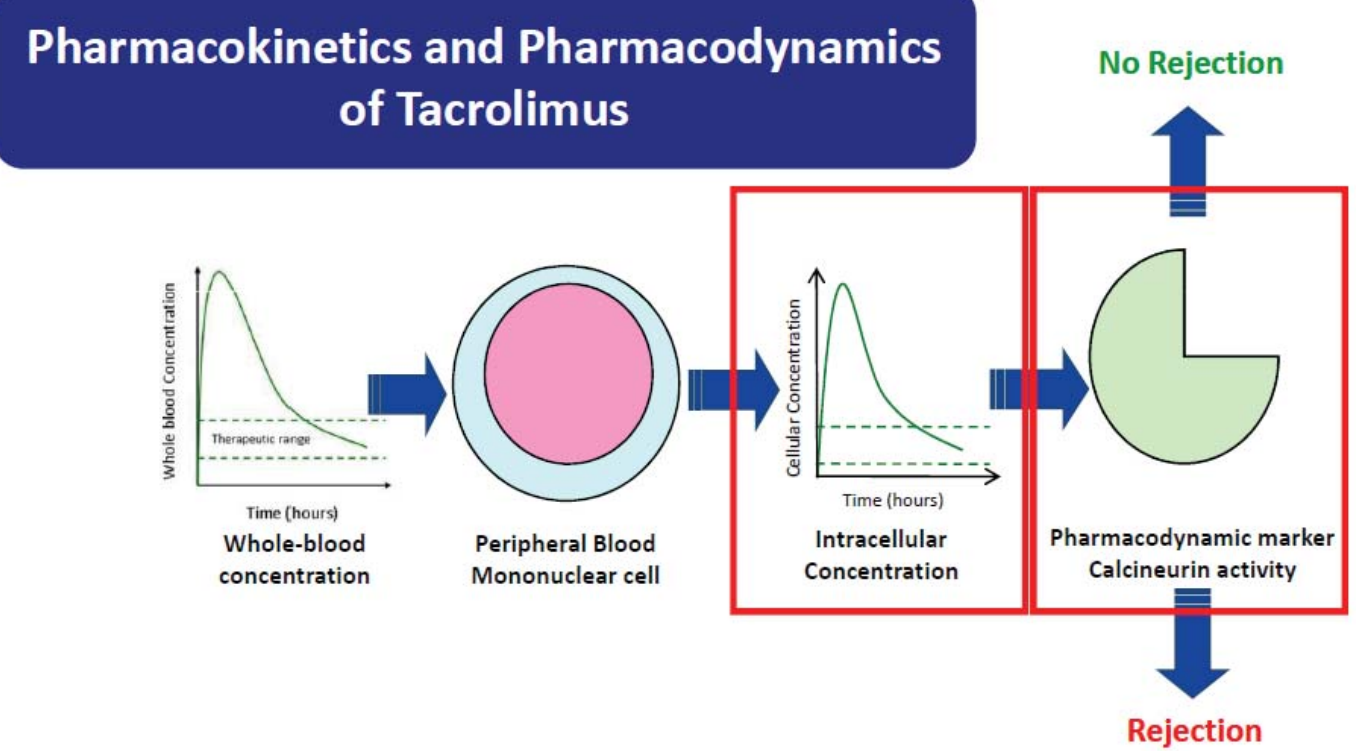

Graphical abstract 
Highlights :

- The pharmacokinetic-pharmacodynamic relationship of tacrolimus (TAC) is detailed

- The first complete intracellular pharmacokinetics of TAC are shown in this study

- Interest of monitoring intracellular TAC and/or calcineurin activity is suggested 